\title{
ASAS/WHO ICF Core Sets for ankylosing spondylitis (AS): how to classify the impact of AS on functioning and health
}

\author{
A Boonen, ${ }^{1} \mathrm{~J}$ Braun, ${ }^{2}$ I E van der Horst Bruinsma, ${ }^{3}$ F Huang, ${ }^{5}$ W Maksymowych, ${ }^{4}$ \\ N Kostanjsek, ${ }^{6}$ A Cieza, ${ }^{7}$ G Stucki, ${ }^{7}$ D van der Heijde ${ }^{8}$
}

- An additional figure is published online only at http:// ard.bmj.com/content/vol69/ issue1

${ }^{1}$ Department of Internal Medicine, Division of Rheumatology, Maastricht University Medical Centre, Maastricht, The Netherlands;

${ }^{2}$ Ruhrgebiet Centre for Rheumatology, Herne, Germany and Benjamin Franklin Free University of Berlin, Department of Rheumatology, Berlin, Germany: ${ }^{3}$ Department of Rheumatology, VU University Hospital, Amsterdam, The Netherlands: ${ }^{4}$ Department of Medicine, Alberta Heritage Foundation for Medical Research, University of Alberta, Edmonton, Alberta, Canada;

${ }^{5}$ Department of Rheumatology, Chinese PLA General Hospital, Beijing 100853, China;

${ }^{6}$ Classification, Assessment, Surveys and Terminology Team, World Health Organization, Geneva, Switzerland: ${ }^{7}$ ICF Research Branch, WHO FIC Collaborating Centre (MDI). IMBK, Ludwig-MaximiliansUniversity and Department of Physical Medicine and Rehabilitation, LudwigMaximilians-University, Munich, Germany; ${ }^{8}$ Leiden University Medical Centre, Leiden, The Netherlands

Correspondence to: Dr A Boonen, Maastricht University Medical Centre, Department of Internal Medicine, Division of Rheumatology, $\mathrm{P}$ Debyelaan 25, $6229 \mathrm{HX}$ Maastricht, The Netherlands; a.boonen@mumc.nl

Accepted 1 March 2009 Published Online First 11 March 2009

\section{ABSTRACT}

Objective: To report on the results of a standardised consensus process agreeing on concepts typical and/or relevant when classifying functioning and health in patients with ankylosing spondylitis (AS) based on the International Classification of Functioning and Health (ICF). Methods: Experts in AS from different professional and geographical backgrounds attended a consensus conference and were divided into three working groups. Rheumatologists were selected from members of the Assessment of SpondyloArthritis international Society (ASAS). Other health professionals were recommended by ASAS members. The aim was to compose three working groups with five to seven participants to allow everybody's contribution in the discussions. Experts selected ICF categories that were considered typical and/ or relevant for AS during a standardised consensus process by integrating evidence from preceding studies in alternating working group and plenary discussions. A Comprehensive ICF Core Set was selected for the comprehensive classification of functioning and a Brief ICF Core Set for application in trials.

Results: The conference was attended by 19 experts from 12 countries. Eighty categories were included in the Comprehensive Core Set, which included 23 Body functions, 19 Body structures, 24 Activities and participation and 14 Environmental factors. Nineteen categories were selected for the Brief Core Set, which included 6 Body functions, 4 Body structures, 7 Activities and participation and 2 Environmental factors.

Conclusion: The Comprehensive and Brief ICF Core Sets for AS are now available and aim to represent the external reference to define consequences of $A S$ on functioning.

Ankylosing spondylitis (AS) predominantly affects the axial skeleton with inflammation of the sacroiliac joints and spine as the hallmark. ${ }^{1}$ Peripheral arthritis, enthesitis, uveitis, psoriasis and inflammatory bowel disease can add to the burden of the disease. Pain, stiffness, fatigue and limitations in spinal mobility are the main impairments and result in a variety of limitations in activities and restrictions in participation in life situations. $^{2}$ The relationships between impairments, activity limitations and participation restrictions can be influenced by contextual factors, including social support, job demands and personal factors.

Recommendations for outcome assessment of AS were proposed by the ASAS/OMERACT group. ${ }^{3}$ The nine selected domains comprise pain, stiffness, physical function, fatigue, spinal mobility, peripheral joints, enthesis, $x$ rays of the spine and laboratory assessment of inflammation. The ASAS/OMERACT Core Set was not primarily developed to assess the impact of the disease on functioning but to measure all aspects of outcome. Drug toxicity, employment and wellbeing, for example, were part of the candidate domains but not selected in the final core set. Moreover, the ASAS/OMERACT Core Set aims to be a recommendation for the minimal domains to be measured in trials or for clinical record keeping realising that other domains might be relevant. Interestingly, the finally selected domains all belong to the broad concept "functioning". It is important to realise that the selected domain "function" was limited to physical function and that it was not further detailed which aspects of physical function are relevant for the assessment. The selection of the ASAS/OMERACT domains did not include the perspective of non-rheumatologist health professionals or patients and it ignores the relationships among domains. Taken together, it would have advantages in identifying all aspects of "what to measure" when examining the impact of AS on global functioning, based on the perspectives of all stakeholders and departing from a specific model that recognises the complexity of global functioning. Such a detailed selection of subdomains or "building stones" that are relevant for functioning could serve as an external reference. It can be the starting point for the global assessment of patients and also for studying functioning and health and for the development of new instruments. ${ }^{56}$

With the approval of the International Classification of Functioning, Disability and Health (ICF), ${ }^{78}$ one can rely on a universally agreed and understood framework and classification to define the spectrum of problems in functioning of patients. The framework endorses the bio-psycho-social model, recognising the influence of contextual (environmental and personal) factors on functioning and disability. The classification offers a detailed list of ICF categories necessary to describe functioning. In the ICF's hierarchical classification system, each component (body functions, body structures, activities and participation and environmental factors) is described by chapters that contain altogether 1545 categories of the second, third and fourth levels. The third and fourth level categories are specifications of the less specific second level. ${ }^{9}$ It would be neither feasible nor informative to assess all aspects of functioning when knowing that these are not 
typical or relevant for that disease. Therefore, to be able to apply the ICF classification in medicine, the so called ICF Core Sets are developed which are lists of ICF categories specific for that disease. ${ }^{1011}$ The disease-specific Comprehensive ICF Core Set (C-ICF-CS) are selections of ICF categories to guide multidisciplinary assessments and facilitate research on functioning and health, ${ }^{12}$ while the Brief ICF Core Set (B-ICF-CS) can be used to describe patients during clinical studies. ICF Core Sets are developed according to a standardised consensus procedure (SCP), enhancing comparability across disease. ${ }^{13}$

The objective of this paper is to report on the results of the SCP that integrates evidence from preceding studies to develop Comprehensive and Brief-ICF-CS for AS.

\section{METHODS}

Following an SCP, experts in AS from different geographical areas integrated evidence from preceding studies into ICF Core Sets during a 3 day consensus conference (online supplementary figure).

Expert rheumatologists were selected from the full member list of the Assessment SpondyloArthritis international Society (ASAS), assuring representation of all world regions. ASAS members have an established record in the field of AS as membership requires a dedicated interest in spondylitis and a minimum of publications in the field. ${ }^{14}$ Non-rheumatologist expert health professionals were recommended by ASAS members. In line with the standardised approach for all ICF consensus conferences, it was intended to establish three working groups, each consisting of five to seven participants. This number assures representation of the different health professionals and geographical areas and enhances the possibility of contribution of each individual in the discussions.

Preceding studies included qualitative studies to identify which aspects are typical and/or relevant for functioning in AS according to health professionals (Delphi exercise), patients (focus interviews) and outcome research (literature review). ${ }^{11}$ The concepts revealed in these steps were linked to the closest ICF category. In addition, empirical data collection with the ICF checklist among patients provided quantitative information on the relevance of the category for patients. ${ }^{12}$ Overall, 374 ICF categories at the second, third and fourth ICF level were identified in the preceding studies with 93 (24\%) categories on Body functions, 58 (15\%) on Body structures, 146 (38\%) on Activities and participation and 77 (20\%) on Environmental factors.

After the training in the ICF, participants were asked to read the compiled categories from the preceding studies. For each second level category, they were asked to give an individual vote (yes/no) as to whether this category was relevant and/or typical for AS and should be included in the C-ICF-CS. Subsequently, the SCP was started, which involved alternating group and plenary discussions. The Appendix (online supplementary figure) explains in detail the steps and the agreement rules for inclusion and exclusion of the categories. In part I categories from the preceding studies for the C-ICF-CS and in part II categories for the B-ICF-CS were selected. For the C-ICF-CS categories were selected from the list of categories obtained from the preceding studies. The first cycle was intended to decide on inclusion or exclusion of the second level categories and the second cycle to decide on inclusion or exclusion of the more specific third or fourth level categories. Selection of categories for the B-ICF-CS was limited to categories included in the C-ICF-CS and involved individual ranking followed by plenary agreement on the number of categories for each component to be included. For the C-ICF-CS, participants were instructed to choose as few categories as possible but as many as necessary for global assessment. For the B-ICF-CS participants had to consider the minimum number of categories important for clinical trials.

\section{RESULTS}

Nineteen experts (13 rheumatologists, three physiotherapists, one specialist nurse, one occupational therapist and one psychologist) from 12 different countries (12 from Europe, four from North America, one from Asia and one from Mexico and South America each) attended the consensus conference that was held in September 2007 in Nottwill, Switzerland. Each working group comprised rheumatologists, one physiotherapist and one other health professional. Each working group was chaired by a person from a different world region (IEvdHB, Europe; WM, North-America and FH, Asia). The plenary discussions were facilitated by the coordinator (JB).

\section{Comprehensive ICF Core Set}

Tables 1-4 show the ICF categories included in the C-ICF-CS. The 80 categories comprised two categories at the first level (chapters), 54 categories at the second level, 12 at the third level and 12 at the fourth level. The 56 higher level categories (first and second level) were made up of 12 (21\%) categories from the component Body functions, seven (13\%) from Body structures, 24 (43\%) from Activities and participation and 13 (23\%) from Environmental factors. When combining the point of decision on inclusion in the table with decision process described in the Appendix, it is possible to have an approximate impression of the level of agreement for each specific category.

Within the Body functions, the majority of identified categories belong to chapter 7 Neuromusculoskeletal and movement-related functions and chapter 2 Sensory functions and pain. In the plenary discussions it was noted that $\mathrm{b} 6601$ Functions related to pregnancy was identified as relevant in the Delphi by $84 \%$. In a final vote this category was not selected, favouring the opinion of those who felt frequency of impairments in pregnancy were insufficiently examined to decide whether this is typical. Similarly, several experts reminded the group that patients were more susceptible to infections or allergies (b435 Immunological system functions). In the final vote this category was not selected, favouring the argument that this susceptibility is probably subjective, and not supported by research evidence. Further, the category b1801 Body image was discussed. Some argued that patients might suffer emotionally from their altered posture. The final vote favoured those stating that the body image of patients with AS is realistic and not distorted and that the emotional aspects of this "true" change are reflected in b152 Emotional functions.

Of the seven categories at the second level of the component Body structures, five belonged to chapter 7 Structures related to movement. Most categories were further specified into more specific categories. The plenary discussion concentrated first on the relevance of enthesitis, osteoporosis and influence of muscle composition. This resulted in the inclusion of the category s770 Additional musculoskeletal structures related to movement with the three specifications s7700 Bones, s7702 Muscles and s7703 Extraarticular ligaments to cover these aspects of the disease. Further the point was raised that "postural change" is a typical structural impairment with relevant impact on functioning but not represented by a specific ICF category. It was decided to add this higher level structural impairment (structural impairment not covered; s-nc) to the component Body structures. 
Table 1 International Classification of Functioning, Disability and Health (ICF)—categories of the component "Body functions" included in the Comprehensive ICF Core Set for ankylosing spondylitis

\begin{tabular}{|c|c|c|}
\hline ICF code & ICF category title & $\begin{array}{l}\text { Point of decision in } \\
\text { voting cycle* }\end{array}$ \\
\hline \multicolumn{3}{|c|}{ Chapter 1 Mental functions } \\
\hline b130 & Energy and drive functions & Cycle $1 ;$ vote $_{1}$ \\
\hline b1300 & Energy level & Cycle $2 ;$ vote $_{2}$ \\
\hline b1301 & Motivation & Cycle 2; plenary \\
\hline b134 & Sleep functions & 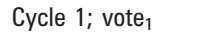 \\
\hline b152* & Emotional functions & Cycle 1; plenary vote \\
\hline \multicolumn{3}{|c|}{ Chapter 2 Sensory functions and pain } \\
\hline b210* & Seeing functions & Cycle 1: plenary vote \\
\hline b280 & Sensation of pain & Cycle $1 ;$ vote $_{1}$ \\
\hline b28010 & Pain in head and neck & Cycle 2; vote $_{2}$ \\
\hline b28011 & Pain in chest & Cycle 2; vote ${ }_{2}$ \\
\hline b28013 & Pain in back & Cycle $2 ;$ vote $_{2}$ \\
\hline b28014 & Pain in upper limb & Cycle 2; plenary \\
\hline b28015 & Pain in lower limb & Cycle 2; vote 2 \\
\hline b28016 & Pain in joints & Cycle 2; plenary \\
\hline b28018 & Pain body part, other specified & Cycle 2; plenary \\
\hline \multicolumn{3}{|c|}{ Chapter 4 Functions of cardiovascular, immunological and respiratory system } \\
\hline b440 & Respiration functions & 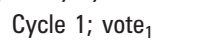 \\
\hline b4402 & Depth of respiration & Cycle 2; plenary \\
\hline b455 & Exercise tolerance functions & 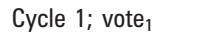 \\
\hline \multicolumn{3}{|c|}{ Chapter 6 Genitourinary and procreation system } \\
\hline b640 & Sexual functions & Cycle $1 ;$ vote $_{2}$ \\
\hline \multicolumn{3}{|c|}{ Chapter 7 Neuromusculoskeletal and movement-related functions } \\
\hline b710 & Mobility of joint functions & Cycle $1 ;$ vote $_{1}$ \\
\hline b740* & Muscle endurance functions & Cycle 1; plenary vote \\
\hline b770 & Gait pattern functions & Cycle $1 ;$ vote $_{1}$ \\
\hline b780 & $\begin{array}{l}\text { Sensations related to muscles and } \\
\text { movement functions }\end{array}$ & Cycle 1; plenary vote \\
\hline b7800 & Sensation of muscle stiffness & Cycle 2; vote ${ }_{2}$ \\
\hline
\end{tabular}

${ }^{*}$ Categories that would not have been selected based on the individual votes; vote ${ }_{1}$, category selected in the first working group discussions of a cycle; vote ${ }_{2}$, category selected in the second working group discussions of a cycle; plenary vote, category selected during the plenary discussion.

Of the 24 categories of the component Activities and participation most belong to chapter 4 Mobility (seven categories) and chapter 5 Self-care (five categories). In the plenary discussions there was split opinion on the inclusion of d240 Handling stress. Some stated that AS does not impair the possibility to handle stress. The plenary vote favoured the argument that there is increasing evidence that acute and chronic inflammation alters the stress response and therefore the disease itself poses an additional challenge to handling stress.

The component Environmental factors was represented by 13 categories at the first or second level of the ICF hierarchy. Most belong to chapter 1 Products and technologies (six categories) and chapter 5 Services, systems and policies (five categories). In the plenary discussion it was specified that the category e580 Health services, systems and policies covers the concept "delay in diagnosis", which had been raised in the Delphi among experts as well as during focus interviews with patients as an important barrier. Further, it was decided to include chapter 3 Support and relationships and chapter 4 Attitudes at the chapter level without specification into lower-level categories (specifying the group of people whose attitudes and support are relevant such as family, friends, health professionals, people in position of authority, etc) because experts found it difficult to decide whose attitudes and support are most relevant for patients. Finally, experts discussed category e225 Climate. Despite some evidence that
Table 2 International Classification of Functioning, Disability and Health (ICF)—categories of the component "Body structures" included in the Comprehensive ICF Core Set for ankylosing spondylitis

\begin{tabular}{|c|c|c|}
\hline ICF code & ICF category title & $\begin{array}{l}\text { Point of decision in } \\
\text { voting cycle* }\end{array}$ \\
\hline \multicolumn{3}{|c|}{ Chapter 2 Eye, ear and related structures } \\
\hline s220 & Structure of eyeball & Cycle 1; plenary vote \\
\hline s2202 & Iris & Cycle 2; vote $_{2}$ \\
\hline \multicolumn{3}{|c|}{$\begin{array}{l}\text { Chapter } 4 \text { Structures cardiovascular, immunological or } \\
\text { respiratory system }\end{array}$} \\
\hline s430 & Structure of respiratory system & Cycle $1 ;$ vote $_{1}$ \\
\hline s4302 & Thoracic cage & Cycle 2; vote $_{2}$ \\
\hline \multicolumn{3}{|c|}{ Chapter 7 Structures related to movement } \\
\hline$s-n c^{*}$ & Postural change & \\
\hline s720 & Structure of shoulder region & 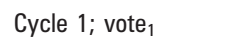 \\
\hline s740 & Structure of pelvic region & Cycle $1 ;$ vote $_{1}$ \\
\hline s750 & Structure of lower extremity & Cycle $1 ;$ vote $_{1}$ \\
\hline s75001 & Hip joint & Cycle 2; vote $_{2}$ \\
\hline \multirow{2}{*}{$\begin{array}{l}s 75011 \\
\text { s75021 }\end{array}$} & Knee joint & Cycle 2; plenary \\
\hline & Ankle joint and joints of foot and toes & Cycle 2; plenary \\
\hline s760 & Structure of trunk & Cycle $1 ;$ vote $_{1}$ \\
\hline s7600 & Structure of vertebral column & Cycle 2; vote $_{2}$ \\
\hline s76000 & Cervical vertebral column & Cycle 2; vote $_{2}$ \\
\hline s76001 & Thoracic vertebral column & Cycle 2; vote $_{2}$ \\
\hline \multirow{2}{*}{$\begin{array}{l}\text { s76002 } \\
\text { s770 }\end{array}$} & Lumbar vertebral column & Cycle 2; vote 2 \\
\hline & $\begin{array}{l}\text { Additional musculoskeletal structures related } \\
\text { to movement }\end{array}$ & Cycle $1 ;$ vote $_{1}$ \\
\hline \multirow{3}{*}{$\begin{array}{l}\text { s7700 } \\
\text { s7702 } \\
\text { s7703 }\end{array}$} & Bones & Cycle 2 ; vote $_{2}$ \\
\hline & Muscles & Cycle 2; plenary \\
\hline & $\begin{array}{l}\text { Extra-articular ligaments, fasciae, } \\
\text { extramuscular aponeuroses, retinacula, septa, } \\
\text { bursae, unspecified }\end{array}$ & Cycle 2; vote $_{2}$ \\
\hline
\end{tabular}

*Categories that would not have been selected based on the individual votes; s-nc, category not covered in the component body structures; vote ${ }_{1}$, category selected in the first working group discussions of a cycle; vote ${ }_{2}$, category selected in the second working group discussions of a cycle; plenary vote, category selected during the plenary discussion.

working in cold and humid environment hampered worker participation, it was concluded that this was an atypical/ uncommon situation and that for overall functioning or health, climate was not a typical (objective) facilitator or barrier.

The asterisks in tables 1-4 denote the categories that would not have been selected based on the individual votes, when accepting a threshold of $75 \%$ agreement. This threshold was chosen because this was the threshold for consensus of a category for the first working group vote. Nine categories were included in the C-ICF-CS that would not have been selected based on the individual votes only.

\section{Brief ICF Core Set}

Of the 56 second level categories from the C-ICF-CS, 19 (35\%) were selected for the B-ICF-CS, of which six (32\%) were from the component Body functions, four (21\%) from Body structures, seven (37\%) from Activities and participation and two (11\%) from Environmental factors (table 5). No category was specified at the lower level.

Although rheumatologists favoured the inclusion of Seeing functions and Structures of the eye as typical for AS, most other health professionals argued against inclusion since they felt attacks are usually temporary without major impairments and that treatment-resistant uveitis is rare. In the final vote Seeing functions were not selected for the Brief Core Set. Using the same argument, the category Structures of the respiratory cage was discussed and not selected. 
Table 3 International Classification of Functioning, Disability and Health (ICF) — categories of the component "Activities and participation" included in the Comprehensive ICF Core Set for ankylosing spondylitis

Point of decision in

\section{ICF code ICF category title} voting cycle*

\begin{tabular}{ll}
\hline $\begin{array}{l}\text { Chapter } 2 \\
\text { d230 }\end{array}$ & Ceneral tasks and demands \\
d240 & Handling stress and other psychological \\
\multicolumn{3}{c}{ demands } \\
Chapter 4 & Mobility \\
d410 & Changing basic body position \\
d415 & Maintaining a body position \\
d430 & Lifting and carrying objects \\
d450 & Walking \\
d455 & Moving around \\
d470 & Using transportation \\
d475 & Driving \\
Chapter 5 & Self-care \\
d510 & Washing oneself \\
d520 & Caring for body parts \\
d530 & Toileting \\
d540 & Dressing \\
d570 & Looking after one's health \\
Chapter 6 & Domestic life \\
d620 & Acquisition of goods and services \\
d640 & Doing housework \\
d660 & Assisting others \\
Chapter 7 & Family and interpersonal relationships \\
d760 & Family relationships \\
d770 & Intimate relationships \\
Chapter 8 & Major life areas \\
d845* & Acquiring, keeping and terminating a job \\
d850 & Remunerative employment \\
d870* & Economic self-sufficiency \\
Chapter 9 & Community, social and civic life \\
d910* & Community life \\
d920* & Recreation and leisure \\
\hline
\end{tabular}

Cycle 1; vote

Cycle 1; plenary vote

Cycle 1; vote $_{1}$

Cycle $1 ;$ vote $_{1}$

Cycle 1; plenary vote

Cycle 1; vote

Cycle 1; vote

Cycle $1 ;$ vote $_{1}$

Cycle 1; vote $_{1}$

Cycle 1; vote $_{1}$

Cycle 1; vote $_{1}$

Cycle 1; plenary vote

Cycle 1 ; vote $_{1}$

Cycle 1; plenary vote

Cycle 1; plenary vote

Cycle $1 ;$ vote $_{1}$

Cycle 1; plenary vote

Cycle 1; plenary vote

Cycle 1; plenary vote

Cycle $1 ;$ vote $_{1}$

Cycle $1 ;$ vote $_{1}$

Cycle 1; plenary vote

Cycle 1; plenary vote

Cycle $1 ;$ vote $_{1}$

${ }^{*}$ Categories that would not have been selected based on the individual votes: vote ${ }_{1}$ category selected in the first working group discussions of a cycle; vote ${ }_{2}$, category selected in the second work group discussions of a cycle; plenary vote, category selected during the plenary discussion.

\section{DISCUSSION}

An SCP integrating expert knowledge on AS and evidence from preceding studies, has led to the definition of the ICF Core Sets for AS. The core sets aim to represent what is typical and relevant for functioning and health in AS. The C-ICF-CS is meant for multidisciplinary assessment and outcome research and the BICF-CS for clinical studies. By using the universally accepted language of the ICF and a standardised approach, comparisons across disease will now become possible. ${ }^{13}$ Since ICF Core Sets will have unique but also shared categories across diseases, this will offer opportunities to specify or generalise intervention programmes or research across disease.

In view of the clinical heterogeneity of AS, experts first agreed that spinal and extraspinal articular disease as well as uveitis were unique and typical manifestations of AS that should be considered when defining the core sets. Other AS-related comorbidities such as clinical inflammatory bowel disease and psoriasis were considered to add to the burden of disease and it was preferred to assess these in separate core sets.

Altogether, 80 categories were selected for the C-ICF-CS and 19 for the B-ICF-CS. Consistent with the consequences of the inflammatory process in the spine, peripheral joints and enthesis, the majority of the categories relate to pain, movement and
Table 4 International Classification of Functioning, Disability and Health (ICF) — categories of the component "Environmental factors" included in the Comprehensive ICF Core Set for ankylosing spondylitis

\begin{tabular}{ll}
\hline ICF code $\quad$ ICF category title & $\begin{array}{l}\text { Point of decision } \\
\text { in voting cycle* }\end{array}$
\end{tabular}

Chapter 1 Products and technologies

e110 Products or substances for personal Cycle 1; vote

e1101 Drugs $\begin{array}{ll}\text { consumption } & \text { Cycle 2; } \text { vote }_{2}\end{array}$

e115 Products and technology for personal use in daily Cycle 1; vote

living
Products and technology for personal indoor and Cycle 1; vote

outdoor mobility and transportation

e135 Products and technology for employment Cycle 1; vote

e150 Design, construction and building products and Cycle 1; plenary technology of buildings for public use vote

e155 Design, construction and building products and Cycle 1; plenary technology of buildings for private use vote

Chapter 3 Support and relationships

e3 Support and relationships

Cycle 1; plenary

vote

Chapter 4 Attitudes

e4 Attitudes

Cycle 1; plenary

vote

Chapter 5 Services, systems and policies

e540 Transportation services, systems and policies

e570 Social security services, systems and policies

Cycle 1; vote ${ }_{2}$

Cycle 1; plenary vote

e575* General social support services, systems and policies

e580 Health services, systems and policies

Cycle 1; plenary vote

Cycle 1; plenary vote

e590* Labour and employment services, systems and Cycle 1; vote ${ }_{1}$ policies

${ }^{*}$ Categories that would not have been selected based on the individual votes; vote $_{1}$ category selected in the first working group discussions of a cycle; vote ${ }_{2}$, category selected in the second work group discussions of a cycle; plenary vote, category selected during the plenary discussion.

mobility. In addition, impairments in energy and drive, sleep and emotional functions as well as restrictions in a large number of activities and life situations (participation) were considered important for the core set. Consistent with the biopsycho-social model of disease, $17 \%$ of all selected categories belonged to the component environmental factors. Experts felt strongly about the role of drugs and of support and relationships as reflected by the inclusion of this category and chapter respectively in the Brief Core Set.

The organisers of the conference took great care to invite experts in AS from different professional backgrounds and different countries. Although not an easy task, it proved useful as became clear during the plenary discussions of categories for which no consensus was achieved in the working group votes. For example, physiotherapists had a strong input to reasons for including b740 Muscle endurance functions and d920 Recreation and leisure, the psychologist contributed arguments when discussing b152 Emotional functions, b1801 Body image and d240 Handling stress, the rheumatology nurse added arguments for inclusion of d910 Community life.

Experts enjoyed the SCP and felt they had achieved an important step in defining functioning in AS. One of the main advantages that were mentioned is that it will help in the study of the complexity of functioning in AS (see article on page 108). ${ }^{15}$ Notwithstanding they also had concerns. The ICF classification and language is not always easy to understand. Also, when selecting categories for the B-ICF-CS, experts encountered difficulties, partly because perspectives of different 
Table 5 International Classification of Functioning, Disability and Health (ICF) — categories included in the Brief ICF Core Set for ankylosing spondylitis

\begin{tabular}{|c|c|c|}
\hline ICF component & ICF code & ICF category title \\
\hline \multicolumn{3}{|l|}{ Body functions } \\
\hline & b280 & Sensation of pain \\
\hline & b710 & Mobility of joint functions \\
\hline & b780 & $\begin{array}{l}\text { Sensations related to muscles and movement } \\
\text { functions }\end{array}$ \\
\hline & b130 & Energy and drive functions \\
\hline & b134 & Sleep functions \\
\hline & b152 & Emotional functions \\
\hline & b455 & Exercise tolerance functions \\
\hline \multicolumn{3}{|l|}{ Body structures } \\
\hline & s760 & Structure of trunk \\
\hline & s740 & Structures of pelvic region \\
\hline & s770 & $\begin{array}{l}\text { Additional musculoskeletal structures related } \\
\text { to movement }\end{array}$ \\
\hline & s750 & Structure of lower extremity \\
\hline \multicolumn{3}{|c|}{ Activities and participation } \\
\hline & $\mathrm{d} 230$ & Carrying out daily routine \\
\hline & $\mathrm{d} 410$ & Changing basic body position \\
\hline & $\mathrm{d} 450$ & Walking \\
\hline & d845 & Acquiring, keeping and terminating a job \\
\hline & d850 & Remunerative employment \\
\hline & $\mathrm{d} 760$ & Family relationships \\
\hline & d920 & Recreation and leisure \\
\hline & $\mathrm{d} 475$ & Driving \\
\hline \multicolumn{3}{|c|}{ Environmental factors } \\
\hline & e110 & $\begin{array}{l}\text { Products or substances for personal } \\
\text { consumption }\end{array}$ \\
\hline & e3 & Support and relationships \\
\hline
\end{tabular}

health professionals diverged, and partly, because it was difficult to judge which categories (within and across components) would actually provide redundant opposed to distinct information about the patients' abilities. It is clear that the core sets are first versions that will need extensive validation (fig 1) not only with regard to "truth" for the entire spectrum of patients and for all perspectives and geographical regions, but also with regard to reliability and feasibility. In rheumatoid arthritis test-retest repeatability of the C-ICF-CS was moderate with agreement for all categories of the core set in $57 \%$ and $59 \%$ of patients for inter- and intrarater (2 week interval) reliability, respectively. Repeatability improved for some categories after collapsing the five-level qualifier system into three levels. ${ }^{16}$ Probably, also the wording of the categories and unfamiliarity of professionals and patients with ICF interviews contribute to the moderate reliability.

Sensitivity to change of the C-ICF-CS 6 months after the start of disease-modifying antirheumatic drugs in rheumatoid arthritis was moderate and associations with changes in disease activity and other patient reported outcomes were weak. ${ }^{17}$ It should be noted also that changes in established outcomes in this trial were low.

One of the future directions for the ICF, therefore, is to measure categories by items (and scores) from existing questionnaires. Applying item response theory (IRT), it was possible to constitute a psychometrically sound interval scale when integrating items from several existing instruments that deal with a similar ICF category; in this case example the category b130 Energy and drive functions. ${ }^{18}$ IRT will also have a role in further validation of the ICF Core Sets to confirm that the categories belong to the same dimension "functioning and health" and identify whether certain categories are redundant. An exploratory study applying IRT to interviews of 111 patients with AS using a preliminary ICF checklist for AS (after exclusion of environmental factors), showed that four categories did not fit the unidimensionality. Category d850 Remunerative employment had a negative misfit, indicating the ability to work does not share the unidimensionality of "functioning" with the remaining categories. The categories (d560 Drinking; d6200 Shopping and d830 Higher education had a negative misfit, which indicates they are too highly correlated or are redundant with other categories. These results need to be confirmed in large patient samples. ${ }^{5}$ The large number of ICF categories included in the C-ICF-CS, with an assessment time between 30 and $45 \mathrm{~min}$, might be a potential drawback. However, it should be realised that functioning is complex and we should not try to reduce the necessary categories with the risk of ignoring an important building block. Further, computer-assisted testing will help in the future to efficiently

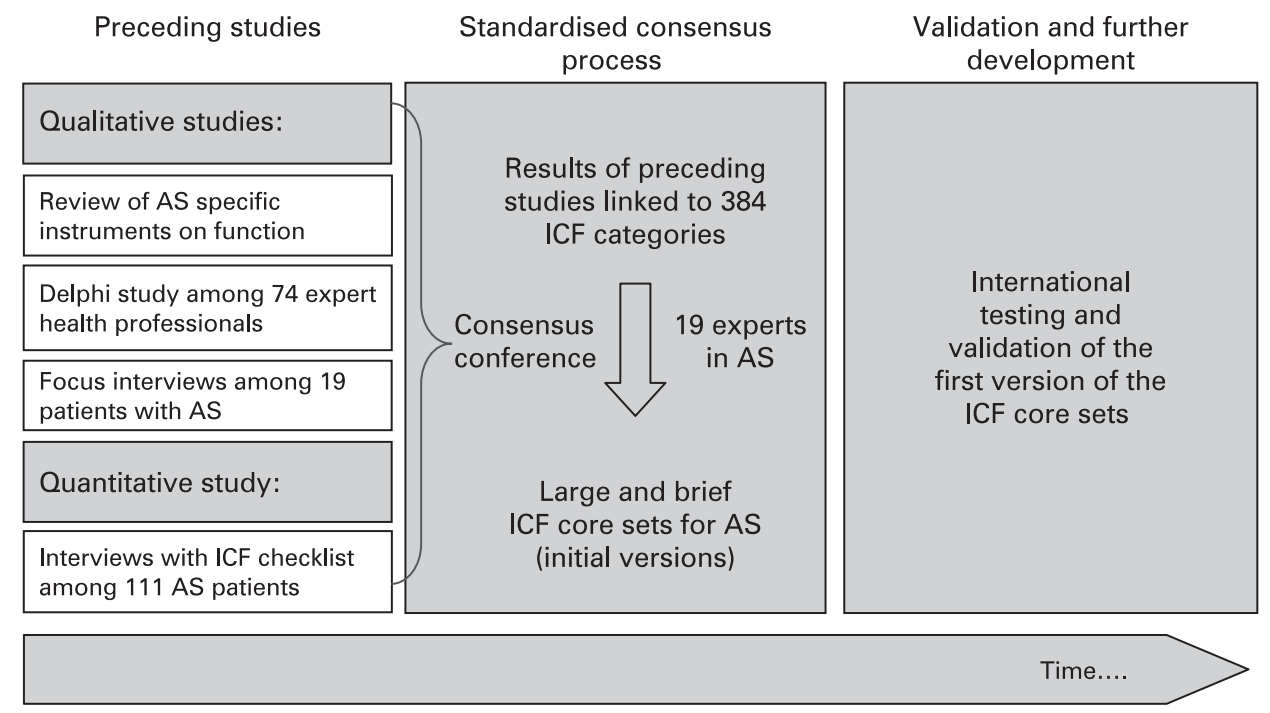

Figure 1 Illustration of the process to develop and further validate the International Classification of Functioning and Health (ICF) Core Set for ankylosing spondylitis (AS). 
measure aspects of outcome in individual patients using only fragments of large computerised item pools. ${ }^{18}$

In conclusion, the C-ICF-CS for comprehensive classification and the B-ICF-CS for clinical studies in AS are now available. The core sets aim to represent the new reference to define functioning in AS and facilitate clinicians' and researchers' efforts to incorporate a patient-oriented, multilevel and comprehensive view on functioning with AS.

Acknowledgements: We thank the Assessment of SpondyloArthritis international Society (ASAS) for the restricted grant to organise the consensus conference. Further, we are most grateful to Marian Curfs and Femke Hoekstra of Maastricht University Medical Centre and to Inge Kirchberger and Silvia Neubert and Areniello Giuseppin of the GA Zäch Research Institute in Nottwil for excellent assistance in the organisation of the conference. Further we acknowledge all participants of the conference without whose unconditional contribution it would not have been possible to define the ICF Core Sets for AS: Jan Brandt (Berlin, Germany), Ruben Burgos Vargos (Mexico City, Mexico), Aileen Davis (FT, Toronto, Canada), Irene van Echteld (Tilburg, Netherlands), Carlos Gonzales (Madrid, Spain), Hilldrun Haibel (Berlin, Germany), Wim van Lankveld (Nijmegen, The Netherlands), Cathy Mallon (Edmonton, Canada), Rikke Helene Moe (Oslo, Norway), Karin Niedermann (Zürich Switzerland), Millicent Stone (Bath, UK), Rafaël Valle-Oňate (Bogota, Colombia), Ulrich Weber (Zurich, Switzerland), Salima van Weelij (Amsterdam, The Netherlands), Ruth Wittoek (Gent, Belgium).

Competing interests: None.

Provenance and peer review: Not commissioned; externally peer reviewed.

\section{REFERENCES}

1. Sieper J, Rudwaleit M, Khan MA, et al. Concepts and epidemiology of spondyloarthritis. Best Pract Res Clin Rheumatol 2006;20:401-17.

2. Sieper J, Braun J, Rudwaleit M, et al. Ankylosing spondylitis: an overview. Ann Rheum Dis 2002:61(Suppl 3):iii8-18.

3. van der Heijde D, Bellamy N, Calin A, et al. Preliminary core sets for endpoints in ankylosing spondylitis. Assessments in Ankylosing Spondylitis Working Group. J Rheumatol 1997:24:2225-9. asd

4. van der Heijde D, Calin A, Dougados M, et al. Selection of instruments in the core set for DC-ART, SMARD, physical therapy, and clinical record keeping in ankylosing spondylitis. Progress report of the ASAS Working Group. Assessments in Ankylosing Spondylitis. J Rheumatol 1999;26:951-4.

5. Cieza A, Hilfiker R, Boonen A, et al. Towards an ICF-based clinical measure of functioning in people with ankylosing spondylitis: A methodological exploration. Disabil Rehabil 2009;31:528-37.

6. Rat AC, Guillemin F, Pouchot J. Mapping the osteoarthritis knee and hip quality of life (OAKHOOL) instrument to the international classification of functioning, disability and health and comparison to five health status instruments used in osteoarthritis. Rheumatology (Oxford) 2008:47:1719-25.

7. Stucki G. International Classification of Functioning, Disability, and Health (ICF): a promising framework and classification for rehabilitation medicine. Am J Phys Med Rehabil 2005;84:733-40.

8. Stucki G, Boonen A, Tugwell P, et al. The World Health Organisation International Classification of Functioning, Disability and Health: a conceptual model and interface for the OMERACT process. J Rheumatol 2007;34:600-6.

9. Anonymous. International Classification of Functioning, Disability and Health. Geneva: World Health Organization, 2001.

10. Cieza A, Ewert T, Ustun TB, et al. Development of ICF Core Sets for patients with chronic conditions. J Rehabil Med 2004;(Suppl):9-11.

11. Stucki G, Grimby G. Applying the ICF in medicine. J Rehabil Med 2004;(Suppl):5-6

12. Stucki G, Cieza A. The International Classification of Functioning, Disability and Health (ICF) in physical and rehabilitation medicine. Eur J Phys Rehabil Med 2008;44:299-302.

13. Schwarzkopf SR, Ewert T, Dreinhofer KE, et al. Towards an ICF Core Set for chronic musculoskeletal conditions: commonalities across ICF Core Sets for osteoarthritis, rheumatoid arthritis, osteoporosis, low back pain and chronic widespread pain. Clin Rheumatol 2008;27:1355-61.

14. ASAS. http://www.asas-group.org (accessed March 2007)

15. Gordeev V, Maksymowych W, Evers S, et al. Role of contextual factors in healthrelated quality of life in ankylosing spondylitis. Ann Rheum Dis 2010:69:108-12.

16. Uhlig T, Lillemo S, Moe RH, et al. Reliability of the ICF Core Set for rheumatoid arthritis. Ann Rheum Dis 2007;66:1078-84.

17. Uhlig T, Moe RH, Reinsberg $\mathrm{S}$, et al. Responsiveness of the ICF Core Set for rheumatoid arthritis. Ann Rheum Dis 2009;68:879-84.

18. Cieza A, Hilfiker R, Boonen A, et al. Constructing interval scales for the measurement of categories of the International Classification of Functioning, Disability and Health. J Clin Epidemiol 2009;31:528-37.

19. Valderas JM, Rue M, Guyatt G, et al. The impact of the VF-14 index, a perceived visual function measure, in the routine management of cataract patients. Qual Life Res 2005:14:1743-53.

\section{Keep up to date: sign up for our alerting services}

Find out automatically when an article is published on a specific topic or by a particular author. We can also alert you when an article is cited or if an eLetter or correction is published. You can also choose to be alerted when a new issue is published online. Check out the New Content Alerts and Citation tracker from the Online tools section on the home page. 


\section{ASAS/WHO ICF Core Sets for ankylosing spondylitis (AS): how to classify the impact of AS on functioning and health}

A Boonen, J Braun, I E van der Horst Bruinsma, et al.

Ann Rheum Dis 2010 69: 102-107 originally published online March 11, 2009

doi: 10.1136/ard.2008.104117

Updated information and services can be found at:

http://ard.bmj.com/content/69/01/102.full.html

\section{Data Supplement}

References

Email alerting service

\section{These include:}

"Web Only Data"

http://ard.bmj.com/content/suppl/2010/01/29/ard.2008.104117.DC1.html

This article cites 12 articles, 4 of which can be accessed free at:

http://ard.bmj.com/content/69/01/102.full.html\#ref-list-1

Article cited in:

http://ard.bmj.com/content/69/01/102.full.html\#related-urls

Receive free email alerts when new articles cite this article. Sign up in the box at the top right corner of the online article. Collections

Articles on similar topics can be found in the following collections
Ankylosing spondylitis (337 articles)
Calcium and bone (583 articles)
Connective tissue disease (3338 articles)
Degenerative joint disease (3627 articles)
Immunology (including allergy) (3942 articles)
Musculoskeletal syndromes (3885 articles)
Rheumatoid arthritis (2535 articles)

To request permissions go to:

http://group.bmj.com/group/rights-licensing/permissions

To order reprints go to:

http://journals.bmj.com/cgi/reprintform

To subscribe to BMJ go to:

http://group.bmj.com/subscribe/ 